\title{
Influence of environmental parameters on bacterial lipids in soils from the French Alps: Implications for palaeo-reconstructions
}

\author{
S. DERENNE ${ }^{1 *}, \mathrm{P} . \mathrm{VEQUAUD}^{1}, \mathrm{~S} . \mathrm{COLLIN}^{1}, \mathrm{C}$. \\ ANQUETIL $^{1}$, J. POULENARD ${ }^{2}$, P. SABATIER ${ }^{2}$, A. \\ HUGUET $^{1}$
}

${ }^{1}$ UMR METIS, Sorbonne Université/CNRS/EPHE, Paris, France $(*$ correspondence : sylvie.derenne@sorbonneuniversite.fr)

${ }^{2}$ UMR EDYTEM, Univ. Savoie Mont-Blanc/CNRS,

Chambéry, France

Microorganisms can modify the composition of their lipid membrane in response to variations in environmental parameters. This is the case for bacterial lipids such as glycerol dialkyl tetraethers (GDGTs) and 3-hydroxy fatty acids (3-OH FAs), both used for temperature and $\mathrm{pH}$ reconstructions in terrestrial paleoenvironmental studies. However, a major concern with these proxies is that their structure may be influenced by other environmental parameters than temperature or $\mathrm{pH}$. The present study aimed at identifying and quantifying the influence of environmental parameters such as soil moisture, vegetation types and soil types on bacterial GDGTs and 3-OH Fas in 49 soil samples collected between $200 \mathrm{~m}$ and 3,000 $\mathrm{m}$ altitude in the French Alps. The soils cover a wide range of temperature $\left(0-15^{\circ} \mathrm{C}\right)$ and $\mathrm{pH}(3-8)$ and are representative of the diversity of soils and vegetation along the investigated altitudinal transects.

Using this well-documented and unique dataset, the GDGT-pH correlation was confirmed, but that between 3-OH FAs and $\mathrm{pH}$ was lower than previously reported. For temperature, correlations were lower than in previous studies for the GDGTs and absent for the 3-OH FAs. Different statistical analyses, allowing for the first time the quantification of the impact of the different environmental factors (temperature, vegetation, soil type...) on the distribution of bacterial lipids, were performed. Redundancy analysis showed that $\mathrm{pH}$ is the main driver of the variability of 3-OH FAs and GDGTs, explaining $20.5 \%$ and $56 \%$ of the distribution of these bacterial lipids, respectively, followed by the altitude and granulometry. This novel understanding of the impacts of environmental parameters will allow refining the use of proxies based on these compounds. Our results pave the way for new types of applications of GDGTs and 3-OH FAs as environmental proxies in paleosoils, peat or lacustrine sediments. 